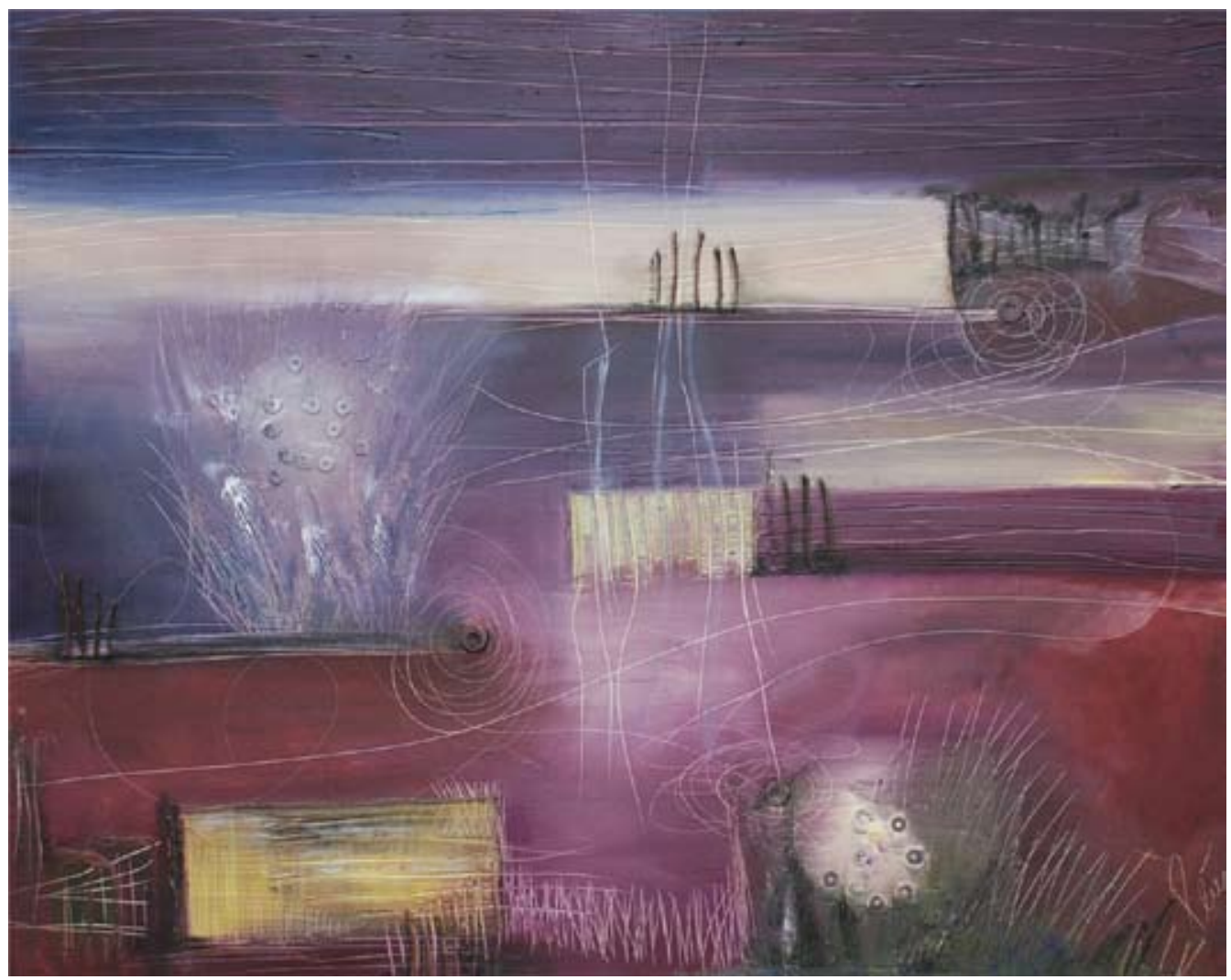

"La luz mala", técnica mixta. María José Pérez 


\title{
¿Y el Estado?
}

\author{
Maria Graciela DI FRANCO
}

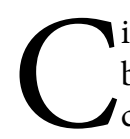

ircula desde marzo de este año un borrador del Plan educativo Maestr@ con expectativa de convertirse en ley. El gobierno nacional busca garantizar la igualdad de oportunidades de aprendizaje y apoyar las políticas de calidad, reafirmando el rol estratégico del derecho a la educación; esto implica cumplir 53 metas que son definidas en el mismo documento.

Se definen dimensiones y líneas de acción: la escolaridad obligatoria (cobertura universal desde 3 años; escuela secundaria; a niños y jóvenes con discapacidad y a comunidades indígenas); la innovación y calidad educativa (buscando mejorar los resultados de aprendizaje, aumentar el tiempo de enseñanza, promover la innovación y generar sistemas de evaluación integrales y confiables); la Formación y Carrera Docente (formación inicial y continua, carrera docente y condiciones salariales); infraestructura y tecnología; Educación Superior, educación y trabajo; seguimiento y financiamiento del Plan. Retoma la legislación educativa desde 1991y se ampara en el propio Plan Estratégico Nacional 2016-2021 "Argentina enseña y aprende".

El documento da cuenta de una relación entre sociedad, escolarización, educación centrada en una perspectiva liberal donde se menciona pobreza, familias más desfavorecidas, abandono, repitencia, desigualdades dando cuenta de una fuerte racionalidad técnica, la cual considera a la sociedad como una trama externa a la escuela, y al currículum como un contexto de análisis de esas necesidades con el fin de adecuar sus programas para alcanzar los objetivos de la sociedad "externa" (Grundy, 1998). No afrontan, ni asumen, ni mencionan, la estructura social de injusticia y sufrimiento que estas mismas concepciones y políticas producen. Al desconocerse esta mirada política cambiar los contenidos, ampliar la carga horaria escolar y las planificaciones docentes será lo necesario a modificar para lograr calidad en la enseñanza. La igualdad de oportunidades en la que se enmarca es igualdad meritocrática de oportunidades. Son oportunidades ofrecidas universalmente, y dependerá de cada individuo que la tome o no, desconociendo las inequidades sociales, culturales, económicas, históricas, que reducen las posibilidades individuales. Será más bien la igualdad de posiciones (Dubet, 2011) la que busque que las distintas posiciones estén más próximas una de otras en la estructura social y puedan reducirse las injusticias.

Se explicitan diagnósticos "naturalizados" sin documentar ni fundamentar que invisibilizan relaciones de poder y reducen las posibilidades de cuestionar que las estructuras sociales no son ni racionales, ni justas y que el rol de Estado debe encaminarse a que dejemos de pensarlas como naturales.

Desde esta racionalidad técnica, el estado anuncia sus roles de planificador y evaluador. Guarda para sí el rol del control pero no garantiza ni financia, y señala la necesidad de convocar a empresas y sindicatos para terminar la escuela secundaria y "atender la demanda no satisfecha de la sociedad”. Después de esta mirada instrumental, de un estado que se desliga de la implementación y el financiamiento 
como políticas públicas irrenunciables, enuncia que "la clave de la educación inclusiva está en los docentes" (p. 10)

En coherencia con esa distancia, el documento justifica mejorar los resultados de aprendizaje como una "necesidad urgente": resultados que se piensan aislados de las condiciones socioculturales, materiales, vitales, validados en un discurso privatizador. Se listan saberes prioritarios, relevantes, emergentes (energías renovables, nuevas tecnologías, espíritu emprendedor) o pendientes (enseñanza de lengua extranjera), vinculados a un discurso de construcción de ciudadanía en contradicción con las prácticas llevadas adelante a diario por esta economía neoliberal.

Para garantizar la perspectiva hegemónica se propone aumentar el tiempo de enseñanza (en días de clase, en extensión de la jornada escolar para primaria y secundaria y las horas de clase efectivas); y promover la innovación pedagógica. Un sistema nacional de evaluación de resultados, prácticas, instituciones y programas cierra el circuito evaluador del estado. Se crea el Instituto Nacional de Evaluación. Nada se evalúa de quiénes formulan estas políticas. Sí el desempeño profesional docente que ingresa y sostiene en el sistema por carrera docente. Será la jurisdicción la que, "según sus posibilidades y realidad económica será la responsable de negociar salarios docentes". La "clave de la educación está en los docentes" de cuyo salario el gobierno nacional no se responsabiliza.

Otros argumentos visibles de esta racionalidad se encuentran en las dimensiones que ocupan en este discurso la infraestructura y la tecnología. Ambas necesarias para la formación enmarcada en la relación educación y trabajo donde la matriz productiva prácticamente define el sentido de la escuela secundaria.

En el capítulo de Educación Superior se reedita la privatización, la fragmentación encubierta en autonomías institucionales, la movilidad de estudiantes y docentes y la internalización del nivel, la educación técnico profesional y la articulación del sistema científico con el sistema universitario. El diagnóstico queda en manos de los CPRES, con un enfoque de planificación descentralizada y regional, con alto nivel de autorregulación del sistema.

La organización federal y el esquema descentralizado del sistema educativo, que consti- tuye el sentido de este documento, justifica un financiamiento diferenciado entre gobierno nacional (infraestructura, tecnología, formación docente y educación superior universitaria) y los provinciales (incremento de la planta docente para asegurar la universalidad de todos los niveles y la extensión de las jornadas en primaria y secundaria). El gobierno nacional se guarda la responsabilidad de controlar, dejando a las jurisdicciones en desiguales condiciones de implementación. Así, la educación como derecho depende de las administraciones provinciales.

Las 53 metas a cumplir hasta el 2016 (algunas contradictorias, ambiguas, indefinidas y sin ningún plan de acción que las concrete) marcan un periodo que supera la extensión de este gobierno, por si debiera dar cuentas por lo actuado. El derecho a la educación se traduce en inversión educativa, gasto público, federalización de la educación, avance en procesos de mercantilización, financiamiento empresarial de la formación profesional, ofensiva neoliberal sobre la universidad pública, flexibilización del trabajo docente, políticas que profundizarán la fragmentación del sistema educativo creando aún más desigualdad.

Para seguir pensando aspectos centrales de la educación desde la investigación educativa crítica, en este número nos acompañan: Juana Irene Castro Rubilar (Universidad del Bío-Bío. Chile); Silvia Branda y Natalia Muñoz (Universidad de Mar del Plata, Argentina); Patricia Belén Demuth Mercado y Erika Yamila Sánchez (Universidad Nacional del Noroeste, Argentina); Cinthia Wanschelbaum (CONICETUniversidad de Buenos Aires, Argentina); María Belén Fernández Massara (UNICEN, Argentina) y Thiago de Souza dos REIS (Universidad Veiga de Almeida, Brasil)

\section{Bibliografía}

Proyecto de Ley Plan Maestr@ file://C:/Documents\%20 and\%20Settings/chachi.JJ/Mis\%20documentos/ Downloads/ProyectodeLeyPlanMaestro\%20(5).pdf

Dubet, F. (2011). Repensar la justicia social. Contra el mito de la igualdad de oportunidades. Buenos Aires, Siglo XXI Editores.

Grundy, S. (1998). Producto o praxis del curriculum. Madrid:Morata 